\title{
A PROPÓSITO DE JURILINGUíSTICA E DE TRADUÇÃO JURÍDICA. New Approach to Legal Translation ${ }^{1}$
}

\author{
Jean-Claude Gémar*
}

\begin{abstract}
Resume: Dans ce texte, l'auteur présente l'ouvrage New approach to Legal Translation, de Susan Sarcevic, considéré par lui comme un traité de traductologie et de jurilinguistique. Il analyse le rôle joué par cet ouvrage dans la jurilinguistique et dans la théorie de la traduction, reprend quelques questions-clés de la traduction juridique au sens strict et de la traduction au sens large, telle que la notion d'équivalence et les nombreuses théories qui fondent la pratique traductive. Partant de là, il partage avec le lecteur sa grande connaissance de la pratique de traduction de textes juridiques, enrichie d'exemples et de réflexions importantes.
\end{abstract}

Mots-clés: jurilinguistique, traductologie, traduction juridique.

Linguista e universitária de origem americana, Susan Sarcevic passou grande parte de sua vida profissional e, portanto, de sua pesquisa, analisando, explorando o texto jurídico sob todos os ângulos e particularmente em situação de tradução em meio bilíngüe e multilíngüe. Ela se manifesta sobre a tradução jurídica na qualidade de jurilinguista, mas fala também como teórica da tradução. Então, seu livro é importante para o mundo da jurilinguística e, em particular, para o da tradução jurídica. Ele se inscreve em uma linhagem já longa de obras que tratam de tradução especializada, mesmo que a jurilinguística e a tradutologia, jovens disciplinas realmente, repousem ainda em bases frágeis, cuja autonomia permanece contestada. A primeira - a jurilinguística - saiu muito oportunamente do caminho em que a confrontação histórica de duas línguas - freqüentemente feita às pressas, por várias razões que não nos interessam aqui - tinha afundado a tradução de textos jurídicos, dentre os quais o das leis em particular, finalmente suplantadas - mas por quanto tempo? - pela co-redação. A segunda - a tradutologia -, igualmente recente, nasceu da necessidade natural do ser humano de se inclinar sobre sua prática e de pensar nela para aperfeiçoá-la e, eventualmente, transcendê-la.

A prática do texto jurídico, quaisquer que sejam sua origem e finalidade, e aquela do texto a ser traduzido não podiam escapar ao movimento geral de teorização dos savoir-faire. O encontro das duas novas disciplinas, postas a serviço do texto jurídico, trouxe resultados, e o nível da reflexão elevou-se. Nesse longo processo, o Canadá exerceu o papel de pioneiro - mas quem ainda ignora isso nos dias de hoje? - tanto em jurilinguística como em tradutologia. Sem a contribuição canadense para a tradução, Susan Sarcevic provavelmente não teria produzido o mesmo livro, pois, nesse estudo, é freqüentemente o Canadá, seus métodos e práticas que estão em questão.

Apesar de sua relativa brevidade (cerca de 300 páginas muito densas), New Approach to Legal Translation é um tratado de tradutologia e de jurilinguística ao mesmo tempo. As duas "abordagens" são, pois, indispensáveis doravante para quem quiser abordar a tradução da

\footnotetext{
${ }^{1}$ Título original: À propos de jurilinguistique et de traduction juridique.New approach to Legal Translation. Publicado em Revue Générale de Droit, Faculté de Droit, section de Droit Civil, n. 31, 2001, p. 391-404. Tradução de Letícia Cobalchini, Bacharel em Letras, UFRGS; revisão de Anna Maria Becker Maciel e Patrícia Chittoni Ramos Reuillard.

* Jean-Claude Gémar, École de traduction et interprétation de l’Université de Genève.
} 
linguagem do Direito de uma maneira menos convencional do que aquela praticada pelos juristas em geral ${ }^{2}$, ou seja, procurar mais o espírito do texto - como um Rossel já o via, na Suíça, no início do Século $\mathrm{XX}^{3}$ - do que a letra. Enfim, ela procurou definir os traços que fazem do texto jurídico um caso particular. De forma suficientemente clara, resulta de sua análise que é a função desse tipo de texto que constitui sua característica, qualquer que seja a função (comunicativa, informativa, conativa, imperativa, etc.) considerada pelos diferentes teóricos e pelas controvérsias que esse termo pode desencadear.

Esse debate pode acabar cansando o leigo, mesmo que apresente um certo interesse para os teóricos e admitindo-se que possa haver entendimento sobre uma função que caracteriza indiscutivelmente o texto jurídico. A linguagem do Direito, portanto, o texto jurídico que ela produz está na língua, francesa, inglesa ou outra. Ora, os linguistas concordam em reconhecer a função referencial como sendo a mais importante da linguagem humana, aquela que reúne todas as línguas. As outras funções resultam dela. A partir daí, qualquer outra função resulta da área, do contexto e da destinação do texto. Se circunscrevermos o texto jurídico essencialmente à lei e ao contrato (mas quid da decisão de justiça?), como fazem a maioria dos linguistas, fica claro que tal tipologia sumária requer a função clássica de regulação (social). Fala-se também, a esse respeito, de texto imperativo, ou ainda, de texto normativo. Pode-se dizer, como a autora (p.11), que a lei ou o contrato são textos essencialmente normativos e que pertencem como tais apenas a esta categoria e que a decisão da justiça e os atos de processo seriam principalmente descritivos e, somente em parte, prescritivos? Uma longa experiência em tradução de textos jurídicos me leva a ver uma realidade menos nitidamente definida. Dir-se-á de uma lei que trata da iluminação de uma dada cidade por bico de gás, descrita pelo legislativo com muitos detalhes, que se trata de um texto essencialmente normativo? Ou ainda, de um contrato de exploração petrolífera, de instalação de gasoduto ou de construção de uma base militar, entre outros exemplos, que o aspecto descritivo nesse caso seja secundário? Além do mais, poder-se-á dizer, por exemplo, de um mandato do Supremo Tribunal, que se trata de um texto essencialmente descritivo e secundariamente prescritivo? Vêem-se aí os limites das tipologias que se baseiam em pressupostos linguísticos e não em realidades jurídicas, as quais são, como quase sempre, nem mais nem menos definidas do que aquelas que se encontram em todas as áreas da atividade humana. Certamente, no topo da hierarquia dos textos normativos, que são as constituições e os tratados, encontrar-se-ão mais normas do que descrições e, na maioria dos julgamentos - e particularmente na tradição anglo-americana -, mais descrições do que normas. Entretanto, esta proporção é muito variável conforme os casos. Aliás, seria tanto útil quanto interessante, para sustentar ou infirmar tais afirmações, fazer, a partir de um corpus bem delimitado de textos pertencentes a uma e outra categoria, um estudo estatístico rigoroso sobre a questão.

A reflexão de Susan Sarcevic é a síntese do essencial do que foi dito ou publicado sobre a questão da tradução jurídica desde que esse tema começou a interessar teóricos da tradução e jurilinguistas. A autora situa claramente seu trabalho em uma perspectiva de comunicação ("legal translation is regarded as an act of communication") (p.3). Assim, todo procedimento teórico, em

\footnotetext{
${ }^{2}$ Sobre esse tema, ver especialmente as atas do $12^{\circ}$ Congresso da Academia Internacional de Direito Comparado (Sidney): " $L a$ traduction juridique", (1987) 28 C. de D. 742. O desafio trata simplesmente do futuro que se reservará a esse tipo particular de tradução, ou seja, traduzir a letra, maneira ainda mais difundida no mundo, ou o espírito do texto de partida.

${ }^{3}$ A respeito do debate que a tradução deste provocou, ver p. 36 e seguintes. Estaríamos enganados acreditando, no entanto, que a língua deve primar sobre o Direito e que o tradutor tem somente uma preocupação na cabeça, aquela de produzir um "bonito" texto. O que um tradutor jurilinguista visa, na realidade, é a "verdade" do texto. Ora, esta verdade jorraria de tal forma do texto que este se tornará legível ao fim de uma interpretação que vai além de seu sentido e de suas significações (a letra) em seguida, de uma re-expressão fiel a seu espírito. Não podemos deixar de pensar no que disse o filósofo Michel Serres: "Freqüentemente o bonito é a explosão do verdadeiro". O mais importante é alcançar o estágio ideal dessa legibilidade, portanto, da verdade do texto. O conteúdo o determina em grande parte. Para se convencer disso, será suficiente comparar dois textos tão diferentes quanto podem ser a Charte canadienne des droits et libertés e a Loi de l'impôt sur le revenu. O prazer e o desejo de leitura do usuário comum da linguagem do Direito flutuarão consideravelmente conforme seu pendor para o primeiro ou para o segundo texto. Não é Stendhal que quer!
} 
matéria de tradução jurídica, deve estar baseado na prática ("practice oriented"). Poucos jurilinguistas, pelo que me consta, contestarão esse postulado. Em seguida, o objetivo confesso dessa obra é tentar corrigir a idéia e a percepção, tanto errôneas quanto tradicionais, que os juristas - mas sem a exceção dos linguistas - têm da tradução jurídica e dar a esta o lugar e a visibilidade que lhe cabem por direito, levando em conta seu impacto no mundo, no seio do grande conjunto das especialidades que se poderia agrupar sob o termo genérico de tradução (médica, técnica, comercial...). Enfim, não se pode esperar encontrar, nessa obra, nem receitas aplicáveis às diversas situações possíveis, nem método(s) milagroso(s), que permitam ao tradutor traduzir melhor o texto jurídico. A própria autora reconhece, com humildade, que talvez não exista um método que se imponha per se e que, provavelmente, seja preferível remeter-se aos métodos particulares e às técnicas em uso nessa cultura e língua jurídicas, assim como o Canadá, entre outros, deu provas. A autora propõe antes à reflexão do leitor e, portanto, do tradutor, um quadro teórico que deveria lhe permitir participar mais ativamente da comunicação jurídica em seu conjunto.

Pode-se dizer, imediatamente, que esse objetivo é alcançado. Dividindo seu livro em duas grandes partes bastante equilibradas, uma teórica (1-4) e uma prática (5-8), a autora fornece um amplo material para reflexão, ao mesmo tempo para o teórico e para o profissional, a prática justificando aqui ainda sua teorização.

No primeiro capítulo, a tradução jurídica é recolocada no contexto geral da tradução e situada no debate teórico, opondo linguistas e juristas. Os dois são confrontados, os primeiros sendo acusados de não terem percebido a função comunicativa própria aos textos jurídicos, e os outros de esquecerem do texto por não verem, no texto a ser traduzido, senão palavras. Ora, a tradução, jurídica ou outra, faz intervirem muitos outros elementos ou aspectos de um texto. Na verdade, a unidade de base, em tradução, é o próprio texto e não sua terminologia (p.5), como a Linguística contemporânea já vem demonstrando há alguns anos. Como resultado disso, os textos podem ser classificados segundo uma tipologia particular, definida pelos teóricos da tradução (p.6), dependendo da função que o texto será chamado a preencher no quadro geral da comunicação: textos religiosos, literários, técnicos, científicos, etc. e, em seus subconjuntos, os textos de especialidade (p. 7-8), dentre os quais se encontra o texto jurídico e sua linguagem particular: a linguagem do Direito. A esse respeito, a autora explica (p.9) que não se preocupou, em sua obra, em descrever essa linguagem e suas características, mas, sim, em analisar o que Gérard Cornu chama de "linguagem do Direito em ação" (p.9). Mais adiante (p. 12 e seguintes), a autora aborda a questão da tradução jurídica sob seus aspectos teóricos e resume brevemente, mas com clareza e exatidão, o estado da reflexão na matéria. Essa parte é essencial, pois trata da questão fundamental de saber o que é a tradução jurídica e em que ela se distinguiria da tradução pura. É bom (re)ver como a resposta para essas questões evoluiu em vinte anos. No estado atual da ciência da tradução, sabe-se que não se traduzem línguas, nem de uma língua para outra, mas sim textos: um texto redigido em determinada língua $=$ um texto redigido em outra. Da mesma maneira, em tradução especializada, não se traduz Direito (ou Medicina, ou Mecânica...) e a seguir uma língua, como pensavam e ainda pensam vários juristas (p.12-14). É um texto que o tradutor deve passar de uma língua para outra, quer o fato cultural seja importante (quem duvidaria disso, em um determinado domínio?) ou não. Constatar-se-á a indiscutível evolução da prática, a partir da Segunda Guerra Mundial, reportando-se às Instruções dadas pelas Nações Unidas a seus tradutores (p.16): mesmo que a fidelidade deva ser o primeiro elemento a ser levado em conta, o tradutor pode dar seu julgamento sobre o plano estilístico, quando precisa lidar, entre outros, com textos jurídicos ou técnicos.

No segundo capítulo, a autora traça a história da tradução jurídica e remonta às suas origens, até o primeiro grande texto jurídico conhecido, aquele do tratado de paz assinado entre os egípcios e os 
hititas (1271 a.C. $)^{4}$, cujo original não se encontrou, mas duas traduções, uma em hieróglifos e outra em escrita cuneiforme. A tradução jurídica não escapou ao debate que opõe, há cerca de dois mil anos, talvez mais, os tradutores entre si, sobre a maneira de traduzir. Consultar-se-á, com grande interesse sobre esse ponto, o quadro proposto pela autora (p. 24), que mostra a evolução da tradução jurídica desde suas origens, que foi do mais literal ao menos literal ou mais livre (a co-redação). Sabe-se o papel que Justiniano I representou para a disciplina, impondo o princípio da tradução literal estrita. A partir de então, o Ocidente liberou-se dessa pressão, apesar de fazê-lo com muita dificuldade, já que restam ainda largos traços na prática contemporânea, mesmo que, nos dias de hoje, os teóricos da tradução apresentem o essencial de seus esforços de análise e de reflexão sobre a língua de chegada (ou língua alvo). Selecionaremos, nessa sucessão de fatos que marcaram a história da tradução jurídica, a tradução em 10 línguas do Código Civil austríaco de 1811 (p.34-35), traduções com fé pública em todas essas línguas!

Aliás, neste livro, quase tudo é questão de "legislativo". A lei ocupa a frente da cena, como entre a maioria dos linguistas, até mesmo juristas tratando da tradução jurídica. Pode-se perceber, sob essa presença, traços do positivismo que marcou o mundo dos juristas sob a influência dos grandes autores do século XIX, entre eles François Gény, para os quais a Lei é o texto jurídico por excelência ${ }^{5}$. Ora, quanto a mim, a tradução da lei (constituição, legislação estadual, tratado...), por mais importante que seja na hierarquia dos textos jurídicos, não é senão um dos vários casos de tradução possíveis e permanece um subconjunto da totalidade que constitui a tradução jurídica, cujo campo estende-se do texto mais pragmático - por exemplo, uma resolução regulamentando a circulação urbana ou o barulho noturno, um contrato de serviços pós-venda - ao mais "estético": um tratado, por exemplo, sobre a norma (ver Hans Kelsen). Isso é fazer pouco caso da imensa maioria dos tradutores que não tocarão jamais em um texto de lei em sua vida - a ponta do iceberg -, pois este é um domínio altamente "reservado", e ignorar os $99 \%$ da prática da tradução jurídica. Entretanto, é por tais iniciativas que se encorajará a criatividade do tradutor. Quando ela é circunscrita ao texto de lei, sabe-se que o tradutor dispõe apenas de um campo de exercício limitado (p. 118 e seguintes.). Aplicada às outras áreas da tradução jurídica, essa criatividade, reconhecida ao tradutor, não pode senão estimulá-lo e, talvez, forçar o jurista a produzir textos melhores. Em todo caso, pode-se esperar que seja assim.

No terceiro e quarto capítulos, a tradução jurídica é tratada sob o aspecto da comunicação, mas essa comunicação ocorre no seio do sistema jurídico e de seu mecanismo (p. 55 e seguintes.). Essa mudança de perspectiva - da transcodificação à comunicação - repercutiu forçosamente no tradutor (p. 87 e seguintes), cujo papel, cada vez menos passivo (simples transcodificador de palavras, devia manter-se fiel à letra do texto a ser traduzido), tornou-se, com o passar do tempo, cada vez mais ativo, a ponto de doravante enxergar em si próprio um "produtor" de texto. A tradutologia, no mesmo grau ou quase que a ciência geral e a pesquisa científica, não teme mais como antigamente a subjetividade do tradutor (ou, em ciências, do pesquisador), a quem se reconhece o direito de intervir, mas não sistematicamente, ao menos em tradução jurídica (p. 91), para interpretar juridicamente o texto. Aqui, a autora visa diretamente minha formulação "dizer o texto".

Essa é a parte teórica, que ocupa aproximadamente um terço da obra. Isso quer dizer que a autora concentrou seus esforços sobre os aspectos práticos da tradução jurídica. Trata-se do estudo

\footnotetext{
${ }^{4}$ Se é verdade que as tábuas de Elba não constituem um texto mais antigo ainda, elas que remontam ao $3^{\circ}$ milênio a.C. Ver sobre a questão G. PETTINATO, Materiali epigrafici di Elba, Roma, Herder, 1982.

${ }^{5}$ Ler-se-á sobre essa questão, com grande proveito, a comunicação apresentada pelo professor N. Kasirer no colóquio internacional de tradução jurídica realizado em Genebra (fevereiro 2000), sob o título de “François Gény's libre recherche scientifique as a Guide for Legal Translation" (La Traduction juridique. Histoire, théorie(s) et pratique, Université de Genève, ETI-ASTTI, 2000, p. 57-85).

${ }^{6}$ Essa afirmação deve ser recolocada no contexto geral da frase, senão ela pode confundir quem não domina algumas sutilezas da língua francesa. Por isso, gostaria de dizer que se a interpretação jurídica pertence, certamente, ao juiz, ao especialista - e não ao tradutor, é claro -, aquela jurilinguística (ver os 5 planos de análise que proponho em Traduire ou l'art d'interpréter, Québec, Presses de l'Université du Québec, 1995, t. 1, p. 187-198), que trata da totalidade - e não de uma parte do texto, pertence ao tradutor.
} 
mais exaustivo e mais explorado sobre o tema que me foi dado a ler. O profissional nela encontrará o que procura, mas também o teórico preocupado em compreender o funcionamento do texto a ser traduzido "em ação" e não apenas em teoria ou em princípio.

No quinto capítulo, dedicado ao que o tradutor deveria saber sobre o texto jurídico, a autora parte do texto jurídico e de seu conteúdo normativo e, como foi dito anteriormente, fundamenta sua análise principalmente sobre o texto legislativo, suas normas e sua estrutura, abordando também o texto judiciário e o tratado. Ela passa em revista diferentes técnicas de redação legislativa, apresenta e compara a estrutura de alguns textos judiciários, insistindo sobre as diferentes concepções em uso, especialmente entre as duas grandes tradições jurídicas representadas pela common law e pelo sistema dito "civilista". A linguística dos "atos de fala" (AUSTIN; SEARLE) inspira largamente suas propostas em que, entre outros, o lado performativo da linguagem do Direito e de seus atos ilocutórios é particularmente valorizado (p. 133 e seguintes.), mas sem negligenciar os critérios jurídicos - e não estritamente linguísticos, como o fazem certos linguistas - que, segundo a autora, devem fundar a classificação dos atos de fala jurídicos. A esse respeito, Susan Sarcevic previne o tradutor jurídico contra a linguística contrastiva (p.137) quando se trata de formular, no texto de chegada, a norma jurídica expressa no texto de partida. É recomendado, antes, dominar o conhecimento dos métodos e das práticas de redação em uso em cada uma das culturas. Ler-se-á com proveito, entre outras, as considerações relativas à obrigação e às autorizações nos textos jurídicos, em particular, a tradução de shall e must, entre outros (p. 137 e seguintes).

O sexto capítulo apresenta um interesse particular no que diz respeito a uma questão muito controversa em tradutologia, a "criatividade" do tradutor. Para alguns, o tradutor não é um criador, já que não faz senão reproduzir o pensamento - o texto, nesse caso - emitido por outra pessoa. Para outros, ele não é um simples "mecânico", mas um engenheiro cujo savoir-faire pode fazer a diferença entre um texto medíocre ou simplesmente banal - a maioria dos textos? - e um texto com boa construção, de uma legibilidade exemplar. Em tradução jurídica, a criatividade tem seus limites, aquele da interpretação jurídica do ou dos textos. Este capítulo trata largamente da co-redação, técnica que o Canadá aperfeiçoou e que parece ter impressionado muito a autora, que vê nisso uma forma, até mesmo um método moderno, acabado e original de tradução. Pode-se ver nessa técnica, de fato, segundo seu contexto de aplicação, algum parentesco com a tradução, especialmente quando os textos produzidos procedem de uma discussão ou de um debate feito em uma única língua. Tratar-se-á, então, de traduzir nas diferentes línguas de chegada - como pode ser o caso em um contexto internacional: ONU, UE, etc. - o texto sobre o qual os protagonistas se entenderão. Outra coisa diferente da tradução será o caso em que os protagonistas debatem, cada um em sua língua, e definem, articulam noções, princípios e regras, que cada um redigirá, em seguida, em sua própria língua, respeitando sua letra e mais particularmente seu espírito. Se a tradução pode ser definida em sentido amplo, como pensam alguns linguistas, como a transposição de um pensamento para uma língua particular, então, sim, pode-se dizer que a co-redação é também uma forma de tradução. Se, por outro lado, considera-se a tradução no sentido mais restrito do termo, aquele no qual se reconhece a tradutologia e que o Petit Robert define nesse sentido, então, co-redação não é tradução ${ }^{7}$. Vejo aí, (certamente, no caso muito particular do Quebec francófono em um Canadá com maioria anglófona), a última forma de expressão de um povo (francófono) que, após ter sido submetido à tradução durante quase dois séculos, conseguiu exprimir-se em sua própria língua ${ }^{8}$.

Deve-se ainda dizer que a co-redação (das leis, contratos, tratados, dicionários...) não revelou todos seus segredos e que representa uma solução e um recurso em boa parte das situações (p.181 e

\footnotetext{
${ }^{7}$ Segundo a edição de 1993: "Texto ou obra fornecendo, em uma outra língua, o equivalente do texto original que se traduziu" (p. 2284).

${ }^{8}$ Daí o subtítulo de meu estudo (Les trois états de la politique linguistique du Québec, Québec, Conseil de la langue française, 1983): "D'une société traduite à une société d'expression". Encontrar-se-ão vários complementos de informação sobre esse problema e sua evolução histórica em uma obra coletiva recentemente publicada sobre o tema: Le français au Québec, 400 ans d'histoire et de vie, Québec, Conseil de la langue française, Les publications du Québec, 2000.
} 
seguintes; p. 208 e seguintes.), apesar dos limites e dos riscos que ela pode apresentar e sobre os quais conclui a autora (p. 194), particularmente no que diz respeito à interpretação (judiciária) dos textos e, portanto, ao conceito de equivalência, cardinal em tradutologia. Essa busca da equivalência, verdadeiro Graal do tradutor - jurídico ou não -, aliás, é objeto do capítulo seguinte, o sétimo, que trata da tradução dos instrumentos multilaterais, os quais, multiplicando-se à medida que aumenta o número dos Estados Partes em um tratado, por exemplo, o de Maastricht, apresentam para o tradutor dificuldades até agora desconhecidas, em particular sobre o plano das concordâncias terminológicas, tratadas no último capítulo dedicado à tradução propriamente dita.

Susan Sarcevic lembra desde o começo (p. 229) que a tradução, jurídica ou outra, não é uma simples transcodificação de palavras (uma palavra = outra palavra), que a busca de "equivalentes" não consiste em substituir uma palavra de uma língua por seu correspondente em outra. Traduz-se texto e não palavras. Ora, a maioria das publicações em jurilinguística favorece as palavras em detrimento do texto. Pode-se ver aí a influência da terminologia, enquanto disciplina, e da tendência descritiva da maioria dos autores. O Direito, para a grande maioria dos juristas, e não dos menores (F. Gény, H. Capitant...), equivale a uma questão de "palavras". Ora, para o tradutor, a palavra não é senão um dos numerosos elementos a ser levado em conta na busca do sentido, ela contribui para dar a ele indicações, mas não pode, sozinha, dizer o texto - a menos que se trate de uma única palavra ou termo constituindo ou representando o próprio texto, como pode ser o título de um livro: Truísmo, Direito flexível, Contrato natural, por exemplo. Susan Sarcevic analisa com detalhes a noção de equivalência e suas conseqüências, e delas propõe graus (p. 327 e seguintes) assim como critérios de aceitabilidade: quando se pode dizer que equivalentes são funcionais, quase funcionais ou não funcionais? O quadro comparativo (inglês-francês) que ela apresenta da noção de hipoteca (p.243) esclarece o princípio um pouco obscuro de equivalência.

Entretanto, mesmo que o princípio de uma instituição, suponhamos o contrato, seja equivalente de um sistema a outro, o campo semântico dessa noção não é idêntico de uma língua e de um domínio a outro. Deve-se, por isso, excluir o princípio de equivalência? Sarcevic lembra com razão, como Mounin proclamava e depois dele Hagège, que se traduz desde sempre, e isso sem se preocupar demasiadamente com o princípio teórico dessa equivalência. Na prática, são os efeitos jurídicos do texto que importam. $\mathrm{E}$ aí, os sistemas divergem quanto aos efeitos jurídicos, exatamente onde "o processo prima sobre o Direito" (René David) e, ao contrário, exatamente onde o Direito é mais importante que o processo, por exemplo, na China. É aqui que os dicionários bilíngues revelam uma parte de seus numerosos limites sendo fracos em descrever a realidade (as realia) tanto linguística quanto jurídica.

Então, qual é a solução? Existiria mesmo uma para isso? Poderíamos encontrar nela um elemento na simetria dos conteúdos de duas versões autênticas (cf. 8.9.2), mas em detrimento do equilíbrio, e por esta razão - no mínimo visual - dos textos: o fundo (a substância) prevaleceria sobre a forma. Sarcevic passa em revista os diferentes procedimentos muito conhecidos dos teóricos da tradução, dentre eles, os empréstimos, decalques e neologismos, sem esquecer os termos e as expressões extraídas do latim e que, sendo às vezes usadas em um sentido que os romanos não tinham pressentido, levantam problemas para o tradutor, até mesmo para os juristas contemporâneos. Nessas condições, a harmonização dos direitos nacionais e de seus vocabulários continua, ao menos para o próximo século, no plano da utopia apesar dos esforços de padronização e dos bancos de terminologia, nas Nações Unidas ou na União Européia, considerando o número dos membros em questão, a não ser que se crie um direito e um vocabulário transnacional. Utopia? O futuro dirá.

No último capítulo, que é também a conclusão de seu livro, Susan Sarcevic esboça o futuro da tradução jurídica e se interroga sobre o modelo que poderia servir de referência, embora seja sempre delicado e mesmo arriscado arrancar uma raiz de seu torrão, (solo) para transplantá-la em uma terra lhe é (seja) estrangeira. Enfim, locus regit actum, nos diz o adágio. Então, o futuro da tradução 
jurídica depende de um modelo, o canadense, por exemplo? Ou melhor, a salvação ou a inspiração do tradutor viriam da teoria do skopos (p. 65) da escola alemã em particular? Não mais, na minha opinião, da estilística comparada (Canadá) ou da teoria do sentido (Paris), que parecem não ter revolucionado a prática do tradutor nem suscitado obras-primas. Se existe obra-prima, deve-se ao talento e à inspiração de grandes tradutores e não a tal método. Aconselha-se portanto ao tradutor ler (e reler) Schleiermacher, Benjamin e outros grandes pensadores da tradução para neles (re)encontrar uma fonte de inspiração bem mais fecunda do que aquela dos "pedagotrads" e outros "teoritrads" (VINAY). A verdade, e isso excepcionalmente, reside sem dúvida na síntese das grandes correntes que se sucederam e que, em um momento ou outro, impuseram cada uma sua verdade efêmera até que fosse suplantada por aquelas das gerações seguintes. Mas sempre restará alguma coisa delas.

Definitivamente, é reconfortante ver que, apesar dos progressos inauditos da técnica, a tradução tem um belo futuro, ela que tem por função primeira fazer os seres humanos se comunicarem entre si. Nesse diálogo, a tradução jurídica é chamada a desempenhar um papel essencial e - por que não? - o de vetor de aproximação de culturas e de indivíduos. É preciso agradecer a Susan Sarcevic por ter produzido este livro e realizado esta síntese. Arco de reflexão contribuindo para elevar o saber comum ao teórico da tradução e ao jurilinguista, o livro ilustra o trabalho ingrato do tradutor de textos jurídicos e com isso o ajuda a refletir tanto em superfície quanto em profundidade sobre sua prática.

\section{BIBLIOGRAFIA}

SARCEVIC, Susan. New Approach to Legal Translation. The Hague, London, Boston: Kluwer Law International, 1997. 